\title{
Klasifikasi Fasies pada Reservoir Menggunakan Crossplot Data Log P-Wave dan Data Log Density
}

\author{
Ismail Zaky Alfatih, Dwa Desa Warnana, dan Priatin Hadi Wijaya \\ Jurusan Teknik Geofisika, Fakultas Teknik Sipil dan Perencanaan, Institut Teknologi Sepuluh Nopember (ITS) \\ Jl. Arief Rahman Hakim, Surabaya 60111 Indonesia \\ e-mail: dwa_desa@geofisika.its.ac.id
}

\begin{abstract}
Abstrak-Klasifikasi fasies merupakan salah satu cara untuk menentukan jenis batuan dari data well log. Telah dilakukan klasifikasi fasies pada reservoir untuk mengetahui persebaran properti dan fasiesnya. Metode yang digunakan ialah crossplot antara data log p-wave dengan data log density. Kontrol dilakukan dengan menggunakan data log gamma ray, log neutron, log porositas dan data core. Data fasies diklasifikasikan menjadi 4, yaitu Super Sandy Globigerina sebagai limestone berpori tinggi sebagai reservoir, Sandy Globigerina sebagai limestone yang didominasi oleh sand, Shaly Globigerina sebagai limestone yang didominasi oleh shale serta Compact Globigerina merupakan limestone kompak tanpa pori.
\end{abstract}

Kata Kunci-Fasies, Globigerina, Limestone, Properti, Reservoir, Well Log.

\section{PENDAHULUAN}

$\mathrm{P}$ engklasifikasian fasies pada reservoir menggunakan crossplot data log p-wave dan data log density dilakukan untuk mengetahui persebaran dari fasies pada reservoir yang dituju. Reservoir yang digunakan ialah reservoir pada blok TG dengan data well TG-1 dan TG-2 dimana disetiap well berisi berbagai macam log seperti log gamma ray, log SP, $\log$ densitas, log neutron, log sonik, log porositas, log resistivitas dan data core.

Dari kesemua log dilakukan crossplot jenis litologi menggunakan kesemua data log yang ada. Setelah diketahui jenis log yang ada maka dilakukan pengklasifikasian jenis batuan sehingga bisa diketahui kemungkinan persebaran lapisan. Dari hasil pengklasifikasian ini perlu diketahui parameter-parameter untuk mendapatkan crossplot yang tepat agar hasil klasifikasi fasies yang didapat cocok.

Oleh karena itu perlu dilakukan klasifikasi fasies menggunakan crossplot data log p-wave dan data log fasies pada penelitian ini untuk didapat hasil crossplot yang cocok untuk digunakan pada pemodelan seismik. Hal ini digunakan karena dengan adanya crossplot tersebut maka bisa dilakukan penelitian lanjutan untuk melakukan pemodelan fasies pada seismik di daerah blok TG nantinya.

\section{TINJAUAN PUSTAKA}

\section{A. Konsep Dasar Analisa Petrofisika}

Analisa petrofisika merupakan suatu evaluasi rekaman logging sumur-sumur eksplorasi untuk mendapatkan litologi dan sifat-sifat petrofisik batuan, seperti saturasi air, besar porositas batuan, kandungan lempung, dan permeabilitas. Sifat-sifat batuan ini diperoleh dari rekaman sifat kelistrikan batuan, tingkat radiasi batuan, kemampuan penjalaran gelombang, dan kerapatan atom-atom penyusun batuan. Dengan pengetahuan mengenai litologi dan sifat-sifat petrofisik batuan, dapat ditentukan interval kedalaman yang merupakan zona reservoir, dan zona produktif. Selain itu, dapat ditentukan pula banyaknya hidrokarbon yang terkandung sesuai dengan kondisi kedalaman dimana hidrokarbon tersebut berada.

\section{B. Konsep Dasar Gamma Ray}
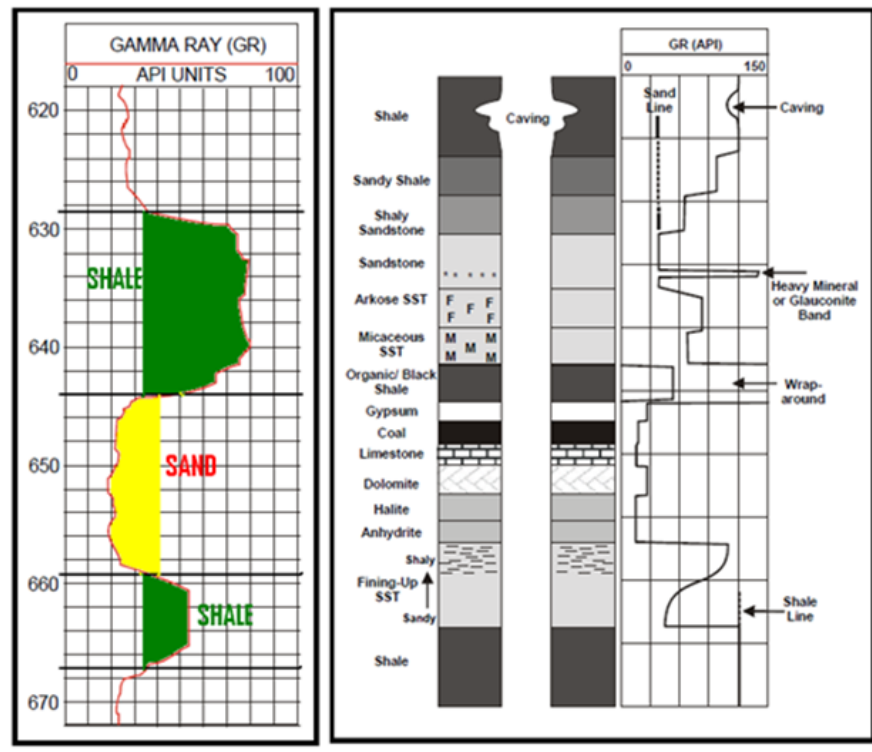

Gambar 1. Contoh analisa log gamma ray efek perbedaan litologi [1]

Log gamma ray (GR) merupakan salah satu aplikasi dari log radioaktif. Prinsip dasar log gamma ray yaitu melakukan pengukuran tingkat radioaktivitas alami bumi. Log gamma ray berfungsi untuk mendeskripsikan suatu batuan yang berpotensi sebagai reservoir atau tidak serta memisahkan batuan permeabel dan shale yang impermeabel. Unsur radioaktif pada umumnya banyak berada pada shale (serpih), sedangkan pada sandstone, limestone, dan dolomit sangat sedikit jumlahnya kecuali pada batuan tersebut terendapkan mineral-mineral yang mengandung unsur radioaktif. Sehingga log ini sangat efektif digunakan untuk melakukan evaluasi formasi pada 
lingkungan pengendapan fluvial deltaic yang sistem perlapisannya terdiri dari sandstone atau shale [2]. Contoh log gamma ray terdapat pada gambar di atas.

\section{Konsep Dasar Density}

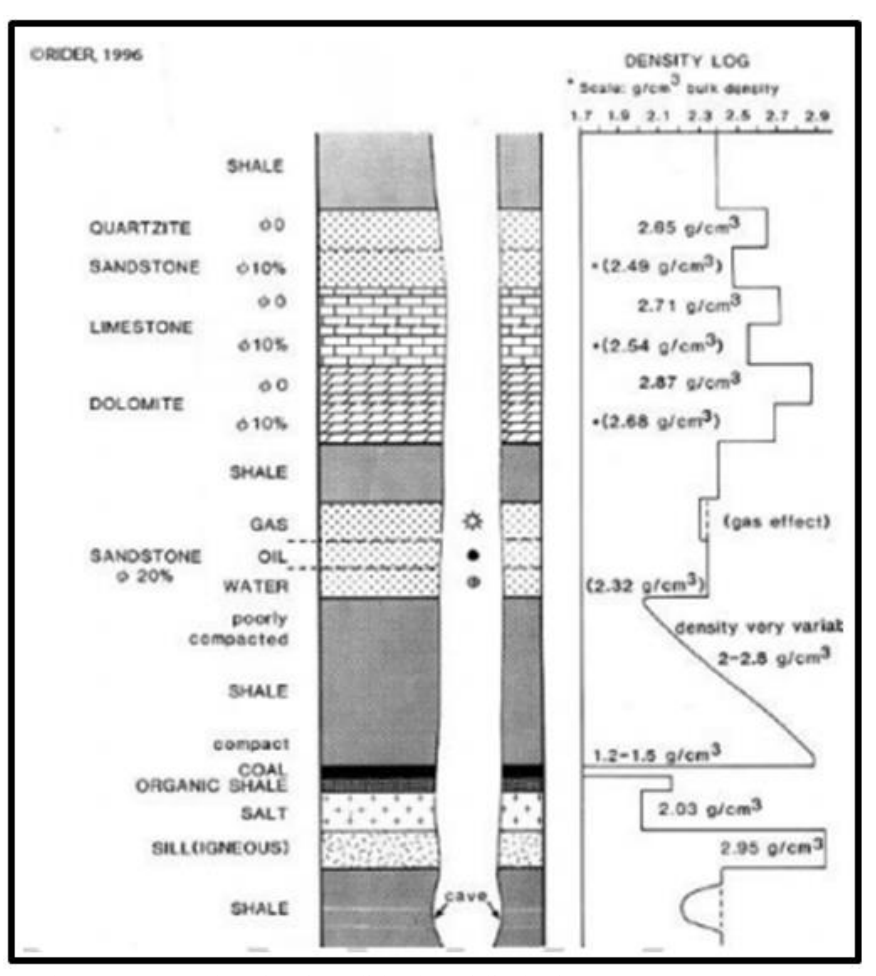

Gambar 2. Respon log densitas di berbagai litologi [1]

Log densitas merupakan salah satu satu log porositas. Prinsip kerja log densitas ini dengan memanfaatkan teori fotolistrik menggunakan sumber radioaktif berupa gamma ray. Sinar gamma ray sebagai foton dipancarkan ke dalam formasi kemudian menumbuk elektron. Semula energi foton cukup besar, saat menumbuk elektron, energi tersebut berkurang karena diserap oleh elektron tersebut untuk melepaskan diri menjadi elektron bebas. Energi yang tersisa membuat foton terus menumbuk elektron lain dalam proses yang sama. Oleh karena itu elektron bebas akan semakin banyak dan elektronelektron tersebut terdeteksi oleh alat densitas. Jumlah elektron yang diserap detektor secara tidak langsung menunjukkan besarnya densitas formasi. [2]

\section{Konsep Dasar Sonic}

Log porositas yang terakhir ini adalah log porositas yang mengukur waktu tempuh (travel time) gelombang akustik di dalam formasi batuan pada jarak tertentu. Selain mencari porositas batuan dan identifikasi batuan, log sonik berguna sebagai informasi utama korelasi dan kalibrasi data log dengan seismik. Dalam proses well-seismic tie dibutuhkan data sonik sebagai fungsi dari impedansi akustik yang kemudian digunakan untuk pembuatan sintetik seismogram. Log sonik ini memiliki besaran $\mu \mathrm{s} / \mathrm{ft}$ atau $\mu \mathrm{s} / \mathrm{m}$ dengan skala $140-40 \mu \mathrm{s} / \mathrm{ft}$ [2]

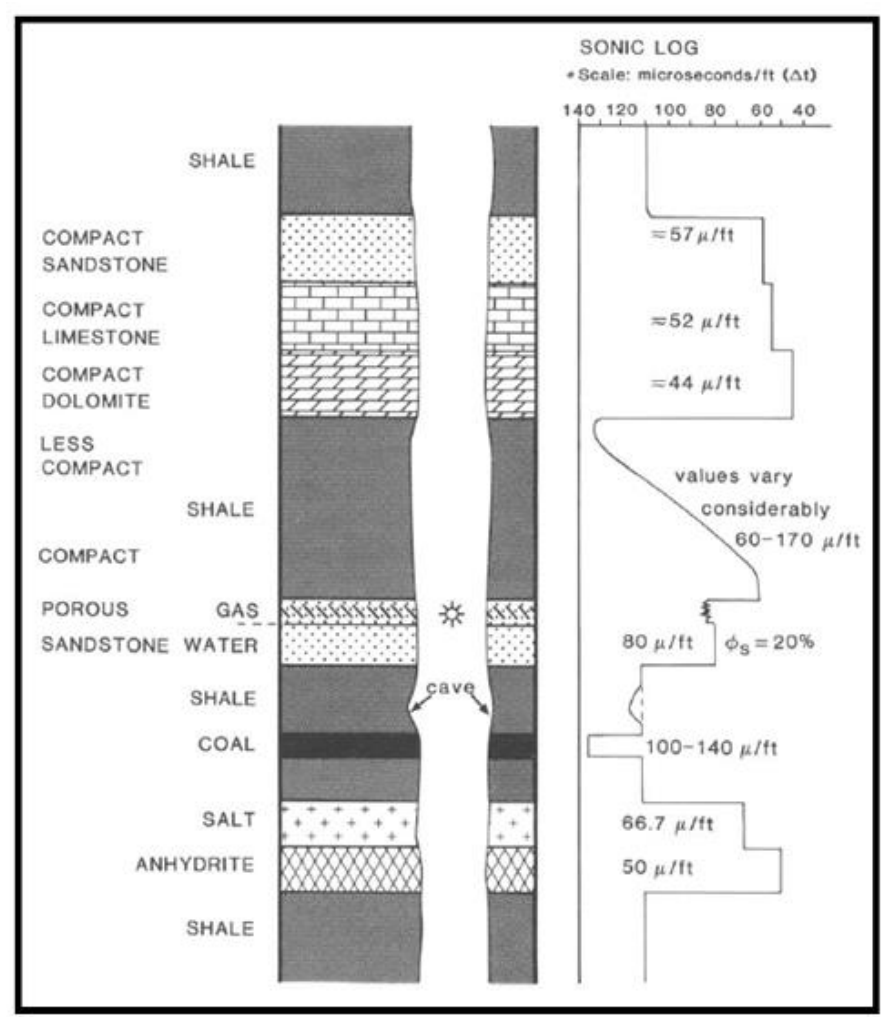

Gambar 3. Respon log sonik di tiap litologi [1]

\section{E. Konsep Dasar Neutron}

Log neutron merupakan salah satu log porositas bersama densitas dan sonik. Log ini termasuk ke dalam salah satu log radioaktif. Pengukuran log neutron dengan cara memancarkan neutron secara kontinu ke dalam formasi batuan. Alat log neutron disebut dengan CNT (Compensated Neutron Tool) atau CNL (Compensated Neutron Log).

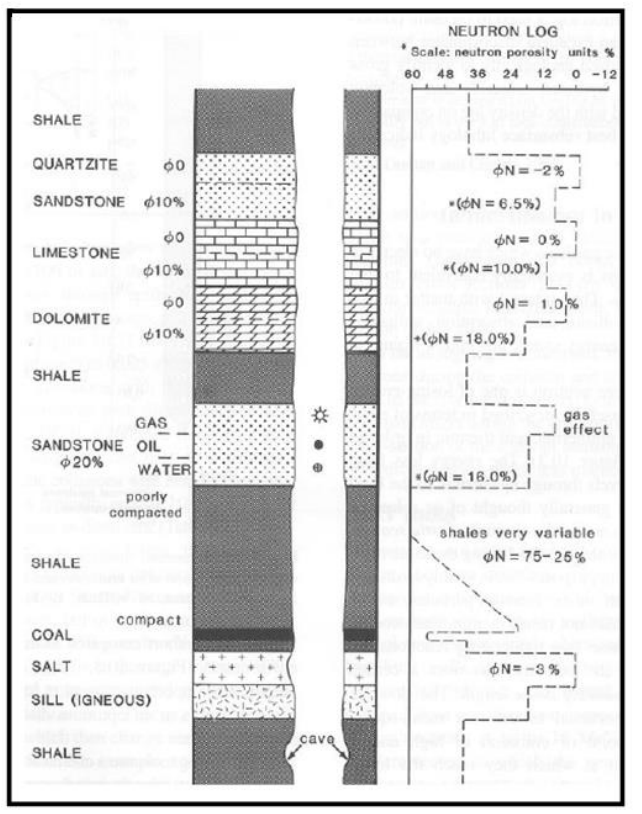

Gambar 4. Tanggapan log neutron pada beberapa kondisi litologi [1] 


\section{METODOLOGI PENELITIAN}

Metodologi penelitian dari penelitian ini adalah dengan melakukan studi korelasi antar log yang ada dan melakukan crossplot antara log densitas dan sonic yang ketika dikalikan merepresentasikan impedansi akustik.

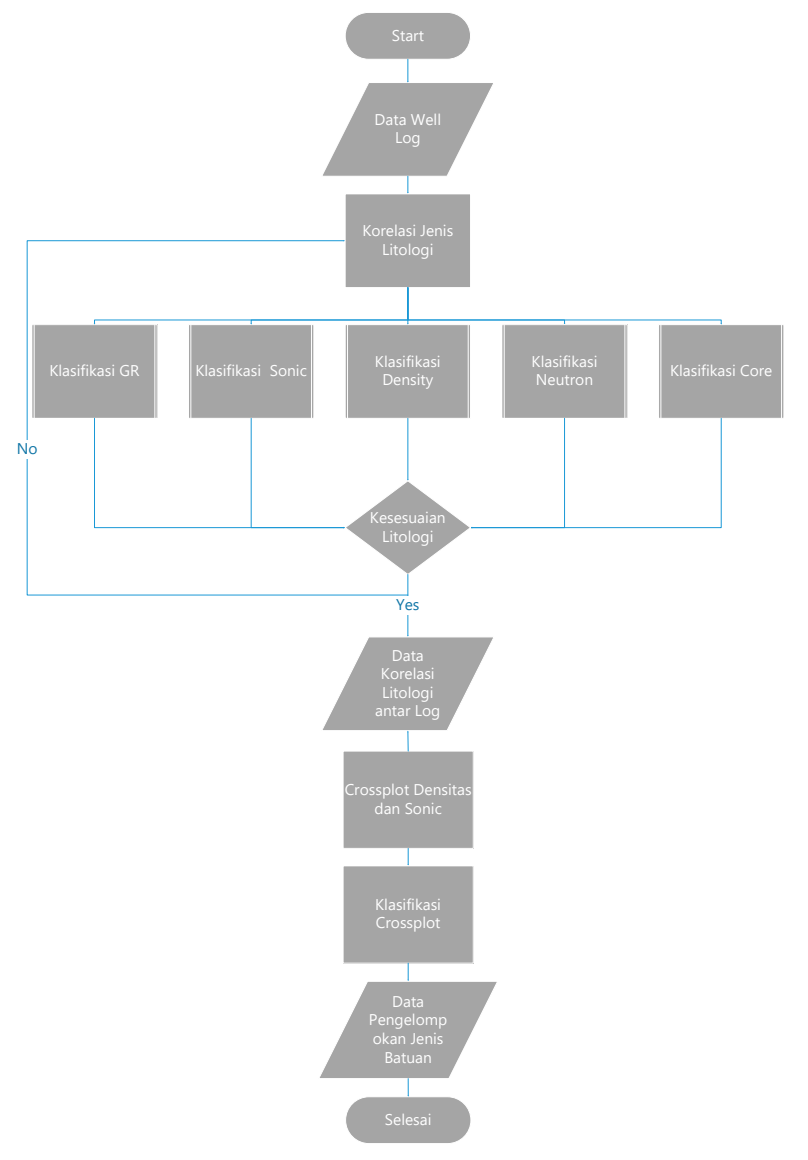

Gambar 5. Diagram Alir Pengolahan Data

\section{HASIL DAN PEMBAHASAN}

\section{A. Korelasi Litologi}

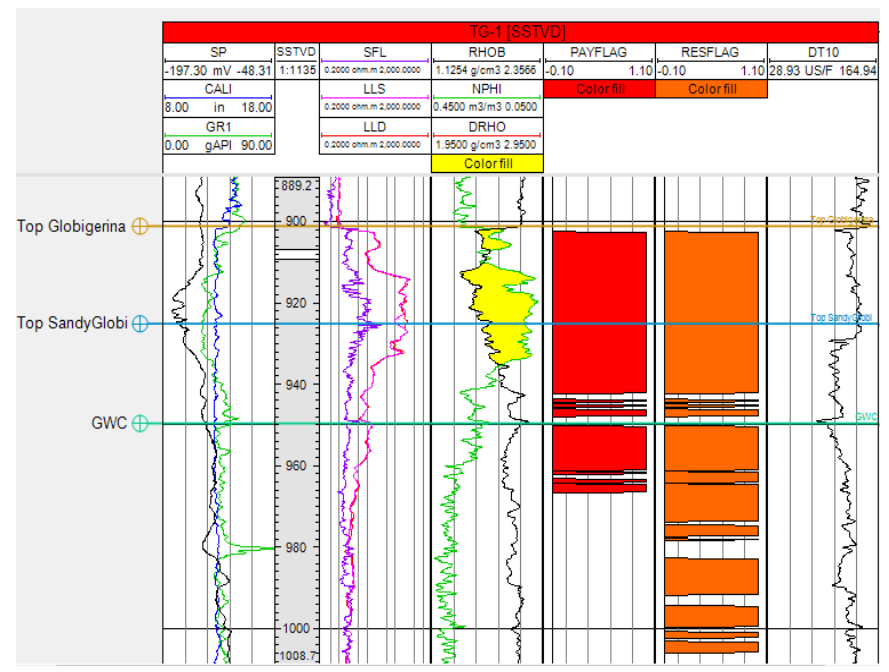

Gambar 6. Penampang Log Well TG-1

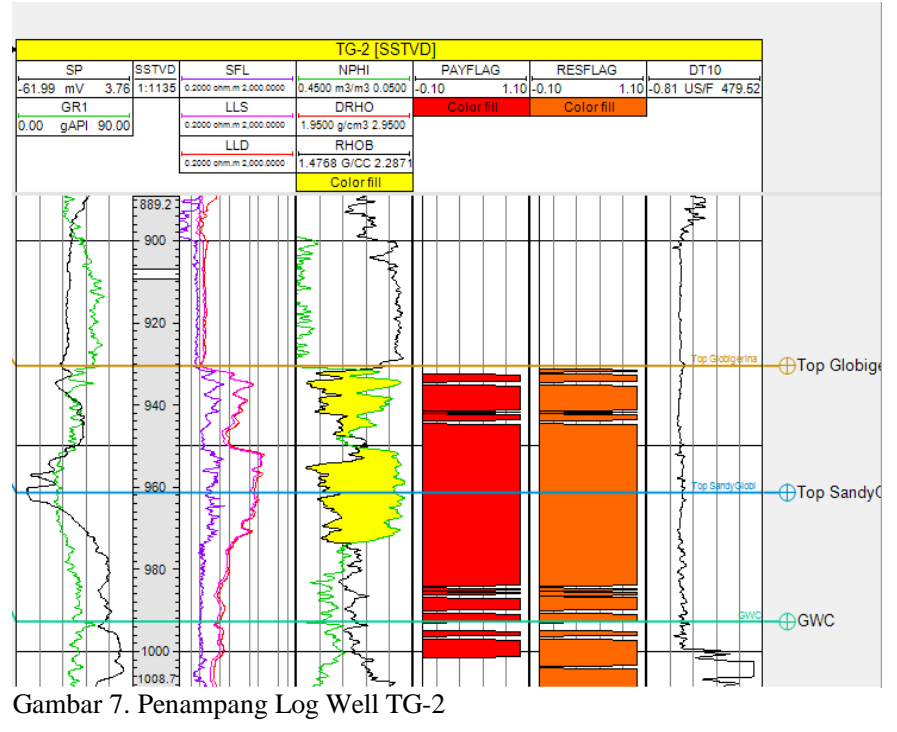

Dari kedua gambar ini bisa kita lihat GR yang ada, porositas, payflag dan resflag. Pada kolom sebelah kanan bisa kita ketahui dari warna orange yang ditunjukkan adalah daerah reservoir (porous-permeable) dan daerah merah merupakan daerah yang memiliki nilai porositas sangat baik dan terisi oleh gas yang merupakan batuan globigerina.

Nilai resflag (zona reservoir) yang didapat pada reservoir di sumur TG-1 dan TG-2 berbeda. Bisa kita lihat gas (Kuning) mengisi pada lapisan sandstone. Karena well berisi data pada lapisan globigerina maka bisa kita lihat bahwa globigerina terisi oleh sand yang akhirnya menjadi tempat dari gas yang ada (reservoir). Sehingga bisa ditarik kesimpulan bahwa lokasi reservoir pada well TG-1 berada di kedalaman 903 - 980 meter, sedangkan pada well TG-2 reservoir berada di kedalaman 930 - 992.5 meter.

Jika dilakukan korelasi antara data well $\log$ dan data referensi milik Glover bisa kita ketahui bahwa sumur TG-1 memiliki nilai 24 api pada daerah reservoir dan pada sumur TG-2 memiliki nilai 27 api pada daerah reservoir. Ini menunjukkan bahwa daerah tersebut adalah zona rentang limestone seperti pada gambar di bawah.

Jika dilakukan korelasi antara data well $\log$ dan data referensi milik Glover bisa kita ketahui bahwa sumur TG-1 memiliki nilai sonic rata rata $128 \mathrm{US} / \mathrm{F}$ dan pada sumur TG-2 memiliki nilai sonic rata-rata $160 \mathrm{US} / \mathrm{F}$. Ini menunjukkan bahwa daerah tersebut memiliki nilai litologi shale. Perbedaan dengan nilai gamma ray ini menunjukkan bahwa daerah tersebut adalah daerah permeable yang memiliki nilai sonic lumayan besar dikarenakan beberapa dari pori pada lime didominasi oleh shale.

Jika dilakukan korelasi antara data well $\log$ dan data referensi milik Glover bisa kita ketahui bahwa sumur TG-1 memiliki nilai density $1.94 \mathrm{~g} / \mathrm{cm} 3$ dan pada sumur TG-2 memiliki nilai density $1.95 \mathrm{~g} / \mathrm{cm} 3$. Hal ini menunjukkan bahwa nilai densitas limestone ketika porositasnya $0 \%$ maka nilai densitasnya $2.71 \mathrm{~g} / \mathrm{cm} 3$ dan ketika porositasnya $10 \%$ maka densitasnya adalah $2.54 \mathrm{~g} / \mathrm{cm} 3$. Maka dari itu bisa diketahui bahwa dengan nilai porositas 35\%-45\% maka densitas ratarata dari lapangan TG-1 dan TG-2 adalag sekitar $2 \mathrm{~g} / \mathrm{cm} 3$. 
Jika dilakukan korelasi antara data well $\log$ dan data referensi milik Glover bisa kita ketahui bahwa sumur TG-1 memiliki nilai neutron $8-12 \%$ dan pada sumur TG-2 memiliki nilai neutron $7-13 \%$. Hal ini menunjukkan bahwa nilai neutron yang ada adalah limestone dengan porositas lebih dari $10 \%$.

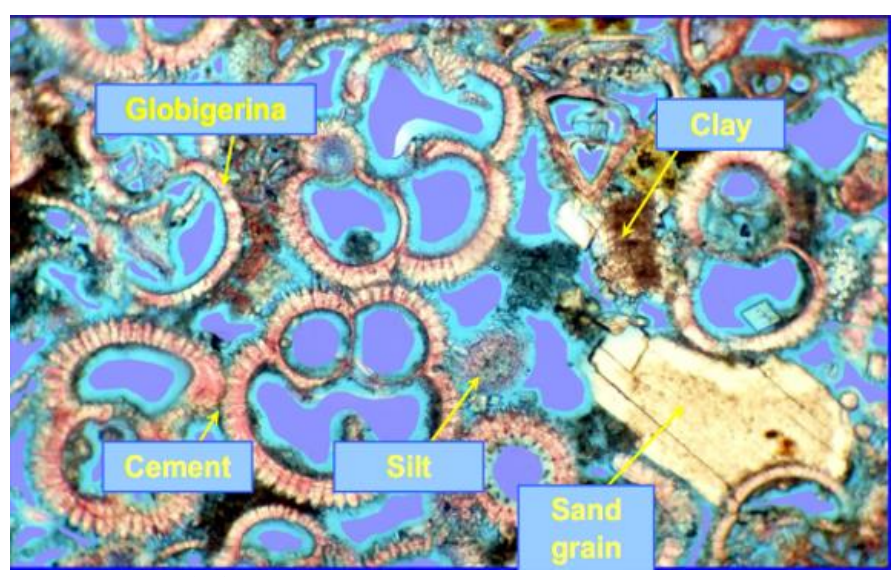

Gambar 8. Korelasi Core

Pada data core didapat nilai porosity total adalah $45 \%$ dan nilai permeability $300 \mathrm{md}$. Serta diketahui bahwa pada core terdapat fossil globigerina sebagai matriks pengisi utama sehingga bisa dikatakan bahwa batu tersebut adalah batu kapur atau limestone serta terdapat pula clay dan sand yang mengisi pori.

Maka dapat disimpulkan bahwa reservoar berada dalam lingkungan Limestone Globigerina dengan data core porosity total $45 \%$ dan permeability $300 \mathrm{md}$.

\section{B. Crossplot Densitas dan P-Wave}

Pada interpretasi fasies, digunakan pembagian kelompok jenis batuan, karena dari data geologi reservoir merupakan batuan globigrinit limestone, maka pada reservoir batuan globigrinit tersebut dibagi lagi klasifikasinya menjadi 4 berdasarkan nilai densitas dan $\mathrm{p}$-wave (sonic) nya yang didapat dari data $\log$.

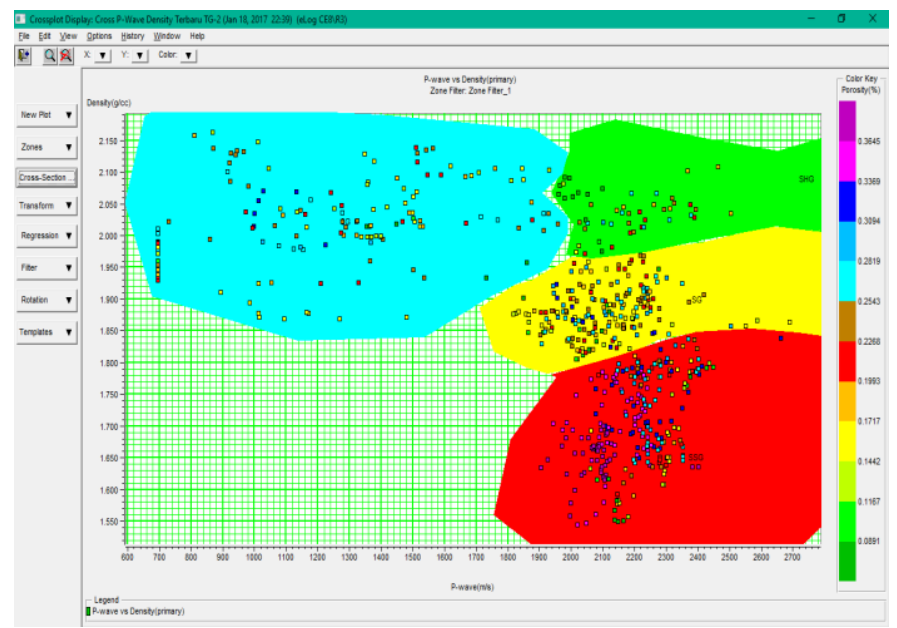

Gambar 9. Pengklasifikasian Facies Batuan Reservoir Globigerina Menurut Data Log Density dan Log Sonic
Yaitu merupakan batuan globigrinit yang kompak dan masih utuh, sehingga batuan tersebut memiliki pori yang sangat kecil dan merupakan reservoir yang buruk walaupun menurut Glover densitas dari batuan ini masih dianggap sebagai reservoir.

\section{- Shaly Globigrinit}

Yaitu merupakan batuan globigrinit yang tidak kompak namun rekahan yang ada terisi oleh shale sehingga walaupun batuan ini memiliki densitas yang besar ia tetap tidak kompak dan masih memiliki pori. Hal ini ditunjukkan oleh besarnya nilai p-wave (sonic) nya. Karena menurut Glover, nilai sonic yang tinggi (di atas $100 \mathrm{us} / \mathrm{ft}$ ) merupakan shale dan densitas $2.5 \mathrm{gr} / \mathrm{cm} 3$ merupakan limestone solid dan dibawah itu menunjukkan limestone berpori. Sehingga pada pengelompokkan shaly globigrinit ini menunjukkan keberadaan limestone globigrinit yang memiliki pori dan terisi oleh shale.

\section{- Sandy Globigrinit}

Sandy globigrinit merupakan limestone globigerina yang memiliki pori dan terisi oleh batuan pasir. Batuan pasir disini bukanlah batu pasir kuarsa yang memiliki densitas yang tinggi, melainkan merupakan batuan pasir hasil pecahan dari batuan globigerina tersebut dan mengisi pori-pori yang ada. Batuan sandy globigrinit merupakan batuan yang sangat cocok sebagai tempat reservoir karena memiliki pori yang besar.

\section{- Super Sandy Globigrinit}

Super sandy globigrinit adalah limestone globigerina yang memiliki densitas yang sangat kecil, p-wave yang kecil dan porositas yang sangat besar. Ini menunjukkan bahwa batuan ini adalah batuan limestone berpori yang porinya sangat sedikit terisi matriks ataupun terisi dengan butir-butir yang besar sehingga masih menyisakan ruang porous yang besar untuk diisi oleh fluida.

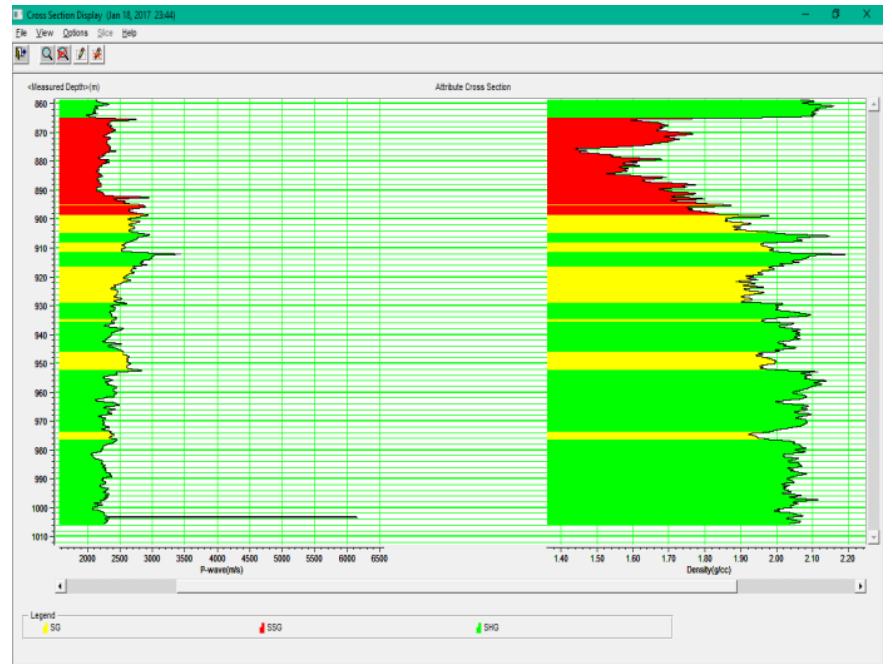

Gambar 10. Hasil Log Densitas dan Sonic dari pengklasifikasian Facies Batuan Reservoir Pada Well TG-1 


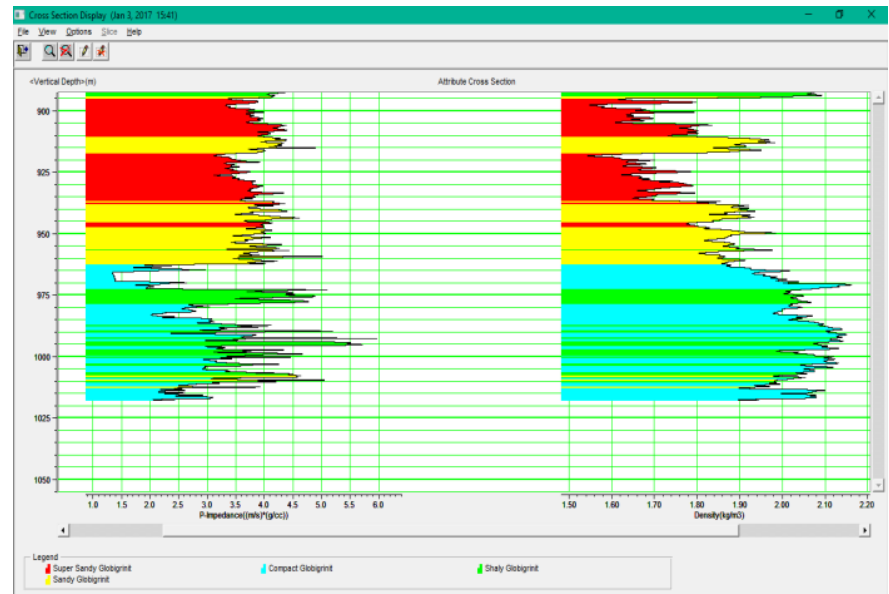

Gambar 11. Hasil Log Densitas dan Sonic dari pengklasifikasian Facies Batuan Reservoir Pada Well TG-2

\section{KESIMPULAN}

Kesimpulan yang didapat dari penelitian ini antara lain.

1. Didapat 4 pengklasifikasian data facies dari hasil crossplot log densitas dan sonic yang terbagi menjadi Super Sandy Globigrinit, Sandy Globigrinit, Compact Globigrinit dan Shaly Globigrinit.

2. Dapat diketahui bahwa lapisan reservoir berada diantara lapisan shale dan sand. Dimana shale berada di atas reservoir dan sand di bawah reservoir

\section{DAFTAR PUSTAKA}

[1] Glover, Paul. 2007. Petrophysics MSc course notes.

[2] Zain, Riki Pahlevi. 2012. Analisis Petrofisika Dan Perhitungan Cadangan Minyak Pada Lapangan "Bear" Cekungan Sumatra Tengah. Tugas Akhir Program Sarjana, Universitas Indonesia. 